\title{
Chapter 10 \\ BRiTE Mind: Introducing Mindfulness \\ to Cultivate Personal and Professional \\ Resilience in Teachers
}

\author{
Helen Correia
}

\begin{abstract}
Mindfulness in education has gained increasing focus over the last decade. Various programmes have been developed for students, teachers and principals, in efforts to improve well-being and resilience in the face of increasing demands and stressors. With teachers often at the forefront of these demands, mindfulness offers the potential to support personal and professional resilience, through enhanced self-awareness, supporting well-being and developing mindful relationships. This chapter describes the development of an online module introducing mindfulness to pre-service teachers, specifically integrating concepts underpinning resilience as outlined in the BRiTE programme. Key elements of mindfulness are explored including mindful attention in the present moment, awareness of emotion and cultivating mindful attitudes, such as compassion. These are applied specifically to teacher experiences to support conscious and mindful action, for personal well-being, and in the classroom.
\end{abstract}

Keywords Mindfulness $\cdot$ Resilience $\cdot$ Teachers $\cdot$ Emotion $\cdot$ Well-being

\subsection{Introduction}

The past decade has seen growing interest in the development and implementation of mindfulness related programmes in education. Mindfulness is increasingly being adopted in classrooms around the world with hopes to improve socio-emotional learning and student well-being (Semple et al. 2017). This growth parallels the increasing popularity of mindfulness and meditation in contemporary secular culture more generally, with an exponential growth in media and scientific articles over the past two decades (Van Dam et al. 2018). Consumerisation of mindfulness tools such as smartphone apps is now being evaluated empirically (e.g. Flett et al. 2019).

H. Correia $(\bowtie)$

Murdoch University, Perth, WA, Australia

e-mail: h.correia@murdoch.edu.au 
The concept of "mindfulness" historically, has its roots in Eastern traditions, defined in many ways. One commonly used definition highlights paying attention, intentionally and on purpose, with awareness of the present moment, in a non-judgemental way (Kabat-Zinn 1994). Similarly, others have identified common elements that include, firstly, present moment awareness, and secondly, the quality or orientation of that awareness (Bishop et al. 2004). These qualities include, for example, non-judgemental acceptance and non-reactivity (e.g. Baer et al. 2006; Blanke and Brose 2017) or care and discernment (e.g. Shapiro 2009). Mindfulness has also been described as a set of meditation practices, a type of skill, a mode of knowing and a way of being (Alper 2016), which are especially supported by formal mindfulness practices. Siegel et al. (2016) distinguish between being in a mindful state, in which we experience moment to moment awareness in a way that allow us to practice openness, acceptance, kindness, mindful traits, which are more enduring characteristic ways of being.

Typically, mindfulness-based interventions include various types of practices, such as meditations, which are intended to consciously induce mindful states. Underpinning these practices are emotional and attentional regulation strategies, aimed to support physical well-being and emotional balance (Lutz et al. 2008). Mindfulnessbased interventions such as Mindfulness-Based Stress Reduction (MBSR), rather than meditation practice alone, typically include additional psychoeducation and contemplative enquiry to support awareness and insight as the basis for change. Within educational contexts the term mindfulness training is also used to describe more general programmes. Mindfulness training is used here to encompass the broad range of interventions and general programmes that purport to use mindfulness as a foundation.

In school environments, the experience of educator stress and burnout in teachers is recognised with the potential for mindfulness to support resilience in these contexts (Jennings and DeMauro 2017). Here, mindfulness training may lead to several key areas of integration for teachers including self-care, professional reflexivity and transforming student learning (Shapiro et al. 2016). The rise in awareness and popularity of mindfulness tools also suggests the need for accessible information about mindfulness and its relevance and application for teachers. Importantly, mindfulness principles support trans-contextual ways of being, equally applicable and meaningful in cultivating resilience in both professional environments and in personal life. The development of an online module as part of the Building Resilience in Teacher Education (BRiTE) (Mansfield et al. 2016; see Chap. 3) programme is described here as an example. This chapter will begin by exploring the empirical literature on mindfulness interventions in school environments and its relevance to developing resilience for teachers. It will also provide an overview of BRiTE Mind, an online module introducing mindfulness through the BRiTE programme, and the ways in which it is intended to support key BRiTE concepts. 


\subsection{The Impact of Mindfulness Training on Students and Teachers}

In educational contexts, the major focus of potential benefits has been student programmes. The expansion of contemporary mindfulness follows earlier research in medicine and psychology demonstrating positive outcomes of mindfulness-based interventions such as MBSR (Van Dam et al. 2018), initially developed for pain conditions, and subsequently adapted to support mental health and well-being more broadly. For students, the increased implementation of programmes and empirical research in the area have prompted several reviews and meta-analyses over the last decade (e.g. Meiklejohn et al. 2012; Zenner et al. 2014; Maynard et al. 2017; McKeering and Hwang 2019; Šouláková et al. 2019). While these reviews have been mixed in finding support for improved academic outcomes, there is more consistent support for potential benefits for elementary and high-school-aged students in socio-emotional processes and well-being.

Despite the potential benefits, a range of authors recognise the limitations in the research, such as absence of school-collected academic or behavioural outcome data (Felver et al. 2016), or the cultural context in which mindfulness is implemented (Long et al. 2018). All reviews recognise the need for higher quality, appropriately powered studies, that explore longer term outcomes, consistent with more recent critiques of mindfulness-based intervention research more generally (Van Dam et al. 2018). Considerable work is needed empirically to evaluate specific programmes (Semple et al. 2017) and establish consistent findings to inform evidence-based practice (McKeering and Hwang 2019). Further, some authors have also recognised the limitations of programme implementation focused solely on students, instead advocating for multilevel integrated interventions that support both students and teachers (Meiklejohn et al. 2012).

With teachers often at the forefront of increasing demands and stressors, the potential benefits of mindfulness have been promoted by a range of authors for teachers and teacher resilience (e.g. Jennings 2015a) as well as in teacher education (e.g. Zimmerman 2018). Even prior to mindfulness training, increased levels of trait mindfulness in teachers have been associated with reduced symptoms of distress, occupational stress and burnout (Braun et al. 2019) and classroom quality such as emotional support (see e.g. Jennings 2015b; Molloy Elreda et al. 2019). In addition to teacher resilience, Siegel et al. (2016) also suggest that mindful teachers facilitate student resilience through mindful relationships founded in Presence, Attunement, Resonance, and Trust (PART). This potential has resulted in the development of tailored mindfulness-based teacher professional development programmes such Cultivating Awareness and Resilience in Education (CARE) for Teachers (Jennings et al. 2013) as well as mindfulness training more generally. A recent review also suggested potential benefits with pre-service teachers (Birchinall et al. 2019). Empirical research of mindfulness training has evaluated impact on both personal and professional outcomes. 
In terms of personal outcomes for teachers, positive benefits of mindfulness training have included reduced self-reported symptoms of psychological stress and improved well-being (e.g. Benn et al. 2012; Hwang et al. 2017; Roeser et al. 2013; Todd et al. 2019). Studies with pre-service teachers have found mixed results, reporting that mindfulness training compared to control group showed improvements in well-being (Hue and Lau 2015) and emotional clarity and emotion regulation (Kerr et al. 2017) but neither found significant reductions in stress, although mindfulness was predictive of symptoms of stress, depression and anxiety (Hue and Lau 2015). Another study by Garner et al. (2018) found that breathing awareness meditation infused with social-emotional learning demonstrated improved emotional competence compared with a control group of breathing awareness meditation only. The range of mixed findings may in part be due to methodological and programme variations.

In an evaluation of the Community Approach to Learning Mindfully (CALM) programme for teachers, improvements were demonstrated in both self-report and physiological measures such as blood pressure compared to control condition (Harris et al. 2016; cf. Roeser et al. 2013). Reductions in anxiety were also found in mindfulness training through MBSR and the Foundations programme, with MBSR alone showing benefits in depression symptoms (Todd et al. 2019). Mindfulness training has also shown increases in self-compassion (e.g. Roeser et al. 2013; Hwang et al. 2017), benefits to self-regulation (Frank et al. 2015), as well as reduced symptoms of burnout and improved cognitive functioning (Roeser et al. 2013). Other studies have explored impact on sleep, identifying positive benefits to quality and reduced sleep difficulties (e.g. Crain et al. 2017; Frank et al. 2015; Hwang et al. 2017).

These findings are generally echoed in a review of nineteen studies evaluating mindfulness interventions for educators, identifying positive outcomes across most measures of psychological distress, burnout and well-being (Lomas et al. 2017). Similarly, Jennings and DeMauro (2017) summarised and reviewed a range of mindfulness-based training programmes used with teachers such as CARE for Teachers (e.g. Jennings et al. 2013), and Stress Management and Relaxation Techniques (SMART) in Education (see e.g. Benn et al. 2012) demonstrating improvements in stress and well-being, as well as the acceptability and feasibility of use with teachers. The CARE programme in particular has shown positive effects across measures of emotion regulation, stress, burnout and mindfulness (Jennings et al. 2017). While initial results are promising, as with the literature for student mindfulness programmes, it is acknowledged that there is heterogeneity in programme characteristics, as well as empirical studies, with higher quality studies needed with longer term evaluations (Jennings and DeMauro 2017; Lomas et al. 2017). Similar suggestions were noted in a review of the state of research on mindfulness interventions for in-service teachers (Hwang et al. 2017).

Other studies have evaluated the impact of mindfulness training on teacher effectiveness, classroom quality and students. An early review identified potential benefits in teaching self-efficacy, managing classroom behaviour and maintaining supportive student-teacher relationships (Meiklejohn et al. 2012). Others have found a reduction in challenging behaviours in students with a mild intellectual disability following 
teacher attendance at an 8-week mindfulness training programme applying mindfulness to the classroom (Singh et al. 2013). It may also improve beliefs about challenging child behaviour in pre-service teachers (Garner et al. 2018). Evaluation of the CARE for Teachers programme compared to waitlist control (Jennings et al. 2013) and a cluster randomised trial (Jennings et al. 2017) identified improved classroom quality interactions through the domain of emotional support. In contrast, another cluster randomised trial (Hwang et al. 2017) found benefits to personal well-being (e.g. perceived stress, sleep) and students' sense of connectedness to teachers, but not in teaching efficacy or student-teacher relationships. Again, however, differences in outcomes may reflect differences in programme components, implementation or measurement.

Overall, despite the relatively small pool of studies, mindfulness training for teachers as reported in the literature seems to support personal resilience and wellbeing, and in some cases may also generate flow-on benefits to classroom environments and student behaviour. While there is limited literature with mixed findings for pre-service teachers, given the potential impact for teachers more broadly, some authors have suggested there may be potential benefit (Birchinall et al. 2019). There is clearly a need for more high-quality studies and a need to explore how differences in programme design, implementation and measurement may impact on outcomes (Lomas et al. 2017). This may be facilitated by further exploring potential processes and mediational factors that help us understand why mindfulness training, or what aspects of mindfulness, help to make a difference to well-being and resilience.

In particular, improvements in some aspects of mindfulness skills, such as observing, non-judgement and non-reactivity may be of importance and worth emphasising (e.g. Todd et al. 2019). A qualitative synthesis by Hwang et al. (2017) suggests the importance of awareness, and changing relationship to experience, potentially through non-reactivity, in supporting improved relationships and mindful coping to manage difficult emotions. This may highlight the importance of selfcompassion as an important mediator in improved well-being and reduced distress (Roeser et al. 2013). Further, a review by Emerson et al. (2017) suggests that mindfulness and self-compassion may lead to more effective emotion regulation processes and improved teacher efficacy, which together reduce stress. In combination, there is an emerging literature that may help to identify key facets worth highlighting, such as awareness of experience, orientations to experience such as non-reactivity and compassion, and factors related to emotion regulation to manage emotions.

In sum, the empirical research base evaluating the impact of mindfulness training and mindfulness-based programmes in education is heterogenous and complex, mirroring the diverse range of programmes offered in educational settings, and similarly mindfulness training tools, such as mobile phone apps, currently available worldwide. Given the paucity of high-quality studies to contribute to evidence-based practice, reviews of the empirical literature are understandably cautious (e.g. Hwang et al. 2017; Lomas et al. 2017; McKeering and Hwang 2019; Semple et al. 2017). Nevertheless, the potential for mindfulness to contribute to improved resilience, personal well-being and interpersonal relationships in educational contexts remains promising (e.g. Jennings and DeMauro 2017). Importantly, given the frequency of 
reports in the media, educators may be interested in pursuing mindfulness practice independent (or unaware) of any concerns highlighted in the scientific literature.

In the current climate, it seems particularly important to develop easily accessible educational resources that introduce teachers to mindfulness related concepts, to support them in how they may use mindfulness to cultivate personal and professional resilience. BRiTE Mind is an online module introducing mindfulness developed for pre-service teachers, linked conceptually to resilience and embedded within the established online Building Resilience in Teacher Education (BRiTE) programme. Yet pre-service teachers in contemporary education settings are likely to have already heard about mindfulness, may have experience with mindfulness practice, and may be exposed to an accessible range of mindfulness programmes and tools. As such, BRiTE Mind attempts to take account of the complexities in the available literature, recognise existing experience, tools and programmes, and seek to translate these in a way that supports pre-service teachers to navigate how they may apply mindfulness practices and principles, to cultivate resilience in personal and professional contexts.

\subsection{BRiTE Mind: Supporting the BRiTE Programme in Cultivating Mindful Resilience}

The potential for mindfulness to support resilience in teachers is a growing area of academic and professional interest. The core principles of mindfulness, such as being present oriented, with openness, acceptance, clarity and flexibility, may contribute to adaptive appraisals and action regulation that support coping for everyday resilience (Skinners and Beer 2016). The online BRiTE programme provides a framework for understanding and developing resilience in teachers, centred around key concepts in BRiTE: Building resilience, Relationships, Wellbeing, Taking initiative, and Emotions. An overview of how mindfulness may be linked to these concepts is described later.

There are several key aims and intentions in the development of BRiTE Mind. First, it aims to provide an introductory overview of mindfulness related concepts, to support developing resilience as explored through the BRiTE programme. Second, given the availability of mindfulness programmes and tools, the purpose of BRiTE Mind was not to replicate or create another mindfulness training programme, but rather to build and extend knowledge about mindfulness, clarifying common understandings and misconceptions that have been perpetuated in the media (e.g. Van Dam et al. 2018). The intention here was to strengthen a balanced understanding of mindfulness as a concept and a practice rather than setting expectations that it is a quick fix, panacea, designed to encourage individual coping with systemic problems (see Correia and Strehlow 2018; Walsh 2016). With this in mind, a third key aim was to support knowledge translation, with opportunities to scaffold application of mindfulness to personal and professional situations. 


\subsection{Key Elements of Mindfulness and Mindful Practice}

Introducing mindfulness through BRiTE Mind required a framework that could help pre-service teachers translate mindfulness concepts and practice into personal and professional contexts. Given the historical roots of mindfulness, as well as the diverse literature on its secular and empirical development, the semantic ambiguity makes distilling broad perspectives into key concepts challenging (Van Dam et al. 2018). However, while the literature varies, a range of authors have attempted to identify core features and key components, from both contemporary and traditional perspectives. Distinguishing between core features may be helpful given some research identifying that different meditation practices that emphasise different qualities can have different effects (see e.g. Lippelt et al. 2014). In BRiTE Mind, key elements are brought together in a broad framework (see Fig. 10.1).

While other mindfulness practice models are available, the model here is necessarily simplified in order to enhance accessibility and orient introductory understanding about mindfulness. It captures key definitional qualities, is applied to a range of mindfulness meditation practices, and supports application of such qualities to specific personal and professional situations as described in BRiTE. These qualities are obviously interconnected and integrated in practice but are distinguished below.

- Present: Mindfulness practice is present oriented, and the emphasis is typically on immediate experience, as described in definitions (e.g. Bishop 2004). This promotes learning that experiences are impermanent and transient, and practicing letting go, rather than getting caught in the past or the future (Kabat-Zinn 1994). The model also recognises the importance of being fully present and connected with purpose.

- Attention: The gathering of attention in a purposeful way is included in most definitions, considered by some a primary feature of practice (Van Dam et al.

Fig. 10.1 BRiTE Mind framework for demonstrating key features of mindfulness practice, with permissions granted by the Australian Government Department of Education

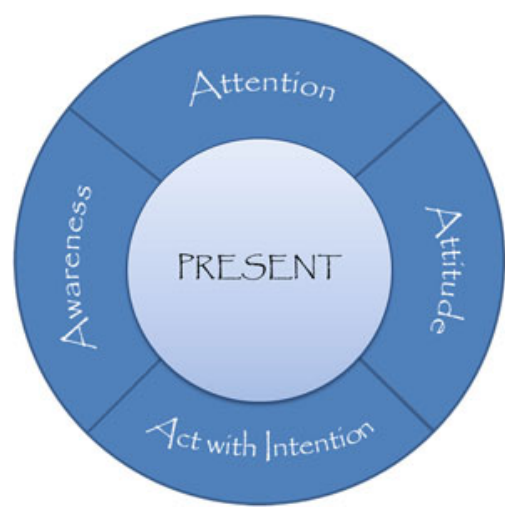


2018). Mindfulness approaches recognise the automatic alerting nature of attention towards salient stimuli and practices attempt to train attention towards intentionality. This includes directing and orienting attention to a chosen object, shifting attention away from distractors back to the selected object of attention and sustaining or maintaining attention (see Jennings 2015a; Lutz et al. 2008).

- Awareness: Attending to present moment experience allows us to tune in and become aware, observing with clarity the stimuli or reactions in our internal and external environments. Open monitoring allows us to observe different stimuli without necessarily becoming attached to any one of them (Lutz et al. 2008). This may include describing through noting or labelling sensations, thoughts, feelings and impulses without acting on them (non-reactivity).

- Attitude: This is intended to capture the attitudes and qualities that provide a context for how we relate to attentional and awareness processes. This includes emotional tone and intentions (e.g. Van Dam et al. 2018), and encompasses ethical values, which are key in teaching practices, especially around reducing harm and suffering, and promoting helpful ways of being. Attitudes of openness, curiosity, non-judgemental acceptance, patience, respect, dignity, compassion and kindness help us to gently observe and act without harmful reactivity, and generate helpful actions.

- Act with Intention: In addition to attention and attitude, some authors emphasise intention (Shapiro et al. 2016), and others suggest that action regulation facilitates coping in teacher resilience (Skinner and Beers 2016). Being mindful, consciously intentional in our actions allows us to respond with conscious intention, choice and flexibility, rather than just acting based on habits and automatic reactions learned from past experience (e.g. attachments and aversions). This reinforces non-reactivity, allowing thoughts, feelings, sensations to come and go, rather than subsuming to automatic or conditioned processes.

In BRiTE Mind, these are applied to typical practices and experiences such as breathing. For example, if experiencing distress and rumination about a difficult classroom experience, bringing attention to the breath in the present moment, tuning in with awareness to observe different sensations, bringing an attitude of nonjudgemental acceptance to those experiences, as well as compassion and care (rather than self criticism) when we become aware our mind has wandered, then acting with intention to redirect attention back to the breath, gently and kindly, time and again. Similarly, it is applied to interpersonal situations such as working with students: we can bring our attention to be truly present with full awareness - we notice, observe, and tune in to what the student is saying with an attitude of openness and curiosity, slowing ourselves down to listen deeply rather than through our own agenda. If we notice our mind has wandered, we bring our attention back to the present interaction, with an attitude of curiosity, kindness and compassion, with conscious intention in how we respond. The combination of these aspects are key in linking to resilience as explored through the BRiTE programme, and are relevant to cultivating resilience in both personal and professional contexts. For example, being mindfully present in family relationships is beneficial both to "switch off from work" to support work-life 
balance, and also in staying present in personal relationships. Examples that highlight these aspects are explored in BRiTE Mind.

\subsection{Links Between Resilience Concepts in BRiTE and Mindfulness Approaches}

Bringing together key concepts in BRiTE Mind provides an underlying framework to support key concepts of resilience outlined in the BRiTE program. Examples with links to teacher applications are provided in Table 10.1. The Emotion module in BRiTE is of key relevance to many resilience concepts in BRiTE, and support awareness of and management of emotions, which is similarly a core feature of mindfulness-based interventions. Shapiro et al. (2016) suggest that mindfulness may promote coping in everyday resilience by reducing reactivity and impulsivity, promoting openness, flexibility and action regulation in response to emotions and adaptive post-event processing of emotions for learning. Empirically, research suggests that mindfulness may improve emotion regulation (Roemer et al. 2015), including for teachers (Emerson et al. 2017). This may be through reducing avoidance (e.g. Prakash et al. 2017) and improving non-reactivity (e.g. Curtiss et al. 2017; Iani et al. 2019). Mindfulness training may also help to reduce reactivity, as well as reduce worry and rumination, which may lead to improved mental health and well-being (Gu et al. 2015). The mindfulness-based CARE programme for teachers specifically found positive benefits for adaptive emotion regulation (Jennings et al. 2017).

To support emotion awareness in particular, BRiTE Mind refers to work by Gilbert (2013) describing a model of emotion regulation systems including threat, emphasising protection from perceived danger, drive (incentive and resource seeking) and affiliative soothing (calming and affiliative focused). The model is part of Gilbert's compassion-based approaches (e.g. Compassionate Mind Training) and is based on research and models in affective neuroscience. Some authors describe a range of other systems (e.g. Panksepp 2005) but the simplified model is intuitive in practice, and facilitates naming, labelling, and exploring the nature of emotional systems, with a recognition of how they may need to change. Gilbert (2013) emphasises the important role of all systems in adaptive emotion regulation, such that underactivity of the soothing system (and/or overactivity of the threat/drive systems) may lead to experiences of chronic stress, highlighting how change might be needed. Further, with the soothing system potentially playing a key role in care, the balance of these systems is argued to be crucial in supporting compassion and developing a compassionate mind (Gilbert 2013). 
Table 10.1 Links between example concepts of resilience in BRiTE and Mindfulness approaches

\begin{tabular}{l}
\hline Example BRiTE concepts \\
\hline Building Resilience: \\
- Adaptive responding to challenges, stressors \\
and demands (both personally and \\
systemically) with sufficient resources in a \\
way that sustains wellbeing.
\end{tabular}
Example links to mindfulness

- Mindful practices (e.g. mindful breathing) to help calm and reduce personal threat reactivity

- Awareness of automatic habits and reactions (personally and systemically)

- Attitudes (e.g. care and discernment, compassion) to acknowledge struggle and motivate changes

- Act with intentions through action regulation to reduce harm and promote adaptive flexible responding (personally and systemically)

Relationships:

- Development and maintenance of positive relationships

- Adapting to new communities

- Working together in teams
- Present and connected through attention and awareness in relationships with students and staff

- Act with intention to bring mindful awareness, attitudes (including ethical values) of non-judgemental acceptance of differences, kindness, compassion to ourselves and others to work together effectively

Wellbeing:

- Developing work-life balance

- Maintaining motivation through persistence and self-efficacy

- Recognising and responding to (dis)stress to support personal well-being
- Awareness of balance/imbalance of demands and resources and the nature of related habits

- Remembering to bring attention to experiences (including distress) with care and discernment, and responding to distress with kindness, compassion and seeking support when needed

- Act with intention around time management to support self-care, maintain attentional presence in non-work activities, and healthy living

- Mindful practices to slow down, observe with non-reactivity, to understand problem situations as they are, and be flexible and adaptive to make choices with intention in response

- Attitudes (e.g. care, compassion) to support making changes to reduce struggle and seek support

- Directing attention with gentle patience and non-judgemental acceptance, kindness, compassion to listen and communicate effectively 
Table 10.1 (continued)

\begin{tabular}{l|l}
\hline Example BRiTE concepts & Example links to mindfulness \\
\hline Emotions & $\begin{array}{l}\text { Awareness of thoughts, physical responses, } \\
\text { - Awareness of and managing emotions } \\
\text { - Developing optimism }\end{array}$ \\
& $\begin{array}{l}\text { impulses, habits, with non-reactivity; act } \\
\text { behaviour }\end{array}$ \\
& $\begin{array}{l}\text { Act with intention through breathing, with } \\
\text { mindful attitudes of openness, curiosity, } \\
\text { non-judgemental acceptance, patience, } \\
\text { compassion }\end{array}$ \\
\hline
\end{tabular}

\subsection{Application to Teacher Experiences-Examples of Mindful Responding in Practice}

One of the key aims was to support knowledge translation of mindfulness approaches into personal and professional experiences. Some examples of mindful responding in practice and application to teacher experiences are provided in Table 10.2. The BRiTE Mind module attempts to bring these kinds of applications to experiences to life through an interactive module, where participants are invited to engage with online activities that promote clarification, observation, reflection and enquiry. For example, in recognising that many individuals may already have experienced mindful moments, participants are invited to share a "mindful moment" to the community, prompted to provide a description that emphasizes awareness and observations of experience rather than a narrative.

In particular, however, participants are invited to explore six case scenarios of typical teacher experiences in personal and professional contexts (developed by Mansfield). These case scenarios are similar to those presented in Table 10.2. Using an interactive web-based tool, participants can generate the likely relative intensity of different emotion regulation systems (threat, drive, soothing), adapted from Gilbert's (2013) model. Participants are also invited to generate examples of possible changes that could be made to improve adaptive responses. For each of the cases, participants are also invited to differentiate between responses that may be more reflective of autopilot/automatic reactivity as compared to the application of mindful approaches to responding, highlighting a key concept from mindfulness-based interventions such as MBSR (e.g. Kabat-Zinn 1994). Participants can also interact with the framework in Fig. 10.1 to generate how each aspect might support the development of mindful responding similar to the examples in Table 10.2, and linked to concepts of resilience in BRiTE.

While BRiTE Mind should be considered an educational resource to support the application of mindfulness rather than a mindfulness-based programme per se, the module does provide links to sample practices, whilst recognising that the development of sustained personal practice is best supported by a mindfulness teacher. In addition, at the end of the module, participants are provided with a range of resources, highlighting empirically evaluated programmes, interventions and tools. 
Table 10.2 Example applications of mindful responses in practice

\begin{tabular}{l}
\hline Example case and BRiTE concepts \\
\hline Case example: Teacher-student conflict: \\
student seems oppositional and seems to \\
encourage other students to act the same \\
- Building Resilience: adaptive responding to \\
challenges, stressors and demands \\
- Relationships: Development and \\
maintenance of positive relationships \\
- Emotions: Awareness of and managing \\
emotions
\end{tabular}

Case example: Teacher is out at a social event and is distracted and pre-occupied with thoughts and about difficulties with a class.

- Wellbeing: e.g. Developing work-life balance, recognising and responding to (dis)stress

- Taking initiative: e.g. Problem solving, Help seeking
Example of mindful approach to teacher experiences

"In the moment, I am aware that my threat system becomes activated - I notice my own self criticism and worry about losing control of the class. I pause to bring mindful attention to my breathing, whilst remaining present in class. This slowing down helps me to "step back", to bring an attitude of acceptance and compassion to the situation, seeing it for what is really is: two human beings feeling threatened, struggling - trying to cope and maintain control over the situation. I remind my self of my ethical values and intentions to play my PART: responding through Presence, Attunement, Resonance, and Trust to respond warmly to the student rather than defensively. An attitude of acceptance also helps me to recognise my difficulties with the situation and act with intention to seek consultation with senior staff."

"While I am out with friends, I notice that my mind keeps wandering to thoughts of work. Rather than get caught up with judging myself about being distracted, I bring warm acceptance and compassionate understanding to recognising that this is because I have high standards and want to solve problems quickly — but I also acknowledge that right now what is helpful for self-care is switching off from work and being present to my relationships. I bring attention to listening, following the conversation. Each time my attention wanders I bring it back to the sounds of others, opening up to the joy around me with an attitude of appreciation. This helps me to feel a sense of safeness and soothing to feel recharged. At work the next day, I use mindful practices to slow down and assess the difficulties with non-reactivity, so I can more easily brainstorm different options that I can raise in the next staff meeting and be open to feedback."

This is intended to support those interested in mindfulness to engage in a more structured process for mindfulness training. 


\subsection{Limitations and Conclusions}

As an introductory module to mindfulness as linked to BRiTE, there are clear limits of what can be included. Given the historical roots of mindfulness, as well as the diverse literature on its secular and empirical development, there is semantic ambiguity in the field, and distilling broad perspectives into key concepts can be challenging (Van Dam et al. 2018). This is especially the case given that mindfulness practices historically have been embedded within years of intense experiential and contemplative training to facilitate insight and understanding. Even as an introductory module, the capacity for BRiTE Mind to improve and clarify understandings of mindfulness related concepts as related to resilience in BRiTE will need to be evaluated through future research. Nevertheless, BRiTE Mind does make an attempt to clarify common understandings, with explicit discussion about misconceptions, whilst balancing this with the potential benefits in application, and supporting the existing empirical literature linking mindfulness training and resilience. One of the strengths of BRiTE Mind is the inclusion of a framework that supports generalisable application of mindfulness qualities and translation of this into personal and professional teacher contexts, which may optimise mindful responding and cultivate resilience in pre-service teachers.

Acknowledgements BriTEMind was developed in collaboration with Caroline Mansfield and Claire Botman, whose ingenuity, creativity, and patience, made BRiTEMind possible.

\section{References}

Alper, S. A. (2016). Mindfulness meditation in psychotherapy: An integrated model for clinicians. Oakland, CA: New Harbinger Publications.

Baer, R. A., Smith, G. T., Hopkins, J., Krietemeyer, J., \& Toney, L. (2006). Using self-report assessment methods to explore facets of mindfulness. Assessment, 13(1), 27-45. https://doi.org/ $10.1177 / 1073191105283504$.

Benn, R., Akiva, T., Arel, S., \& Roeser, R. W. (2012). Mindfulness training effects for parents and educators of children with special needs. Developmental Psychology, 48(5), 1476-1487. https:// doi.org/10.1037/a0027537.

Birchinall, L., Spendlove, D., \& Buck, R. (2019). In the moment: Does mindfulness hold the key to improving the resilience and wellbeing of pre-service teachers?. Teaching and Teacher Education, 86, 102919. https://doi.org/10.1016/j.tate.2019.102919.

Bishop, S. R. (2004). Mindfulness: A Proposed Operational Definition. Clinical Psychology: Science and Practice, 11(3), 230-241. https://doi.org/10.1093/clipsy/bph077.

Bishop, S. R. et al. (2004). Mindfulness: A proposed operational definition. Clinical Psychology: Science and Practice, 11(3), 230-241. https://doi.org/10.1093/clipsy/bph077.

Blanke, E. S., \& Brose, A. (2017). Mindfulness in daily life: A multidimensional approach. Mindfulness, 8(3), 737-750. https://doi.org/10.1007/s12671-016-0651-4.

Braun, S. S., Roeser, R. W., Mashburn, A. J., \& Skinner, E. (2019). Middle school teachers' mindfulness, occupational health and well-being, and the quality of teacher-student interactions. Mindfulness, 10(2), 245-255. https://doi.org/10.1007/s12671-018-0968-2. 
Correia, H. M., \& Strehlow, K. (2018). Mindful Care and Compassion in Higher Education: Cultivating Communities of Practice. In N. Lemon \& S. McDonough (eds.), Mindfulness in the Academy (pp. 189-202). Singapore: Springer. https://doi.org/10.1007/978-981-13-2143-6_12.

Crain, T. L., Schonert-Reichl, K. A., \& Roeser, R. W. (2017). Cultivating teacher mindfulness: Effects of a randomized controlled trial on work, home, and sleep outcomes. Journal of Occupational Health Psychology, 22(2), 138-152. https://doi.org/10.1037/ocp0000043.

Curtiss, J., Klemanski, D. H., Andrews, L., Ito, M., \& Hofmann, S. G. (2017). The conditional process model of mindfulness and emotion regulation: An empirical test. Journal of Affective Disorders, 212, 93-100. https://doi.org/10.1016/j.jad.2017.01.027.

Emerson, L.-M., Leyland, A., Hudson, K., Rowse, G., Hanley, P., \& Hugh-Jones, S. (2017). Teaching mindfulness to teachers: A systematic review and narrative synthesis. Mindfulness, 8(5), 11361149. https://doi.org/10.1007/s12671-017-0691-4.

Felver, J. C., Celis-de Hoyos, C. E., Tezanos, K., \& Singh, N. N. (2016). A systematic review of mindfulness-based interventions for youth in school settings. Mindfulness, 7(1), 34-45. https:// doi.org/10.1007/s12671-015-0389-4.

Flett, J. A. M., Hayne, H., Riordan, B. C., Thompson, L. M., \& Conner, T. S. (2019). Mobile mindfulness meditation: A randomised controlled trial of the effect of two popular apps on mental health. Mindfulness, 10(5), 863-876. https://doi.org/10.1007/s12671-018-1050-9.

Frank, J. L., Reibel, D., Broderick, P., Cantrell, T., \& Metz, S. (2015). The effectiveness of mindfulness-based stress reduction on educator stress and well-being: Results from a pilot study. Mindfulness, 6(2), 208-216. https://doi.org/10.1007/s12671-013-0246-2.

Garner, P. W., Bender, S. L., \& Fedor, M. (2018). Mindfulness-based SEL programming to increase preservice teachers' mindfulness and emotional competence. Psychology in the Schools, 55(4), 377-390. https://doi.org/10.1002/pits.22114.

Gilbert, P. (2013). The Compassionate Mind. London: Constable Robinson.

Gu, J., Strauss, C., Bond, R., \& Cavanagh, K. (2015). How do mindfulness-based cognitive therapy and mindfulness-based stress reduction improve mental health and wellbeing? A systematic review and meta-analysis of mediation studies. Clinical Psychology Review, 37, 1-12. https:// doi.org/10.1016/j.cpr.2015.01.006.

Harris, A. R., Jennings, P. A., Katz, D. A., Abenavoli, R. M., \& Greenberg, M. T. (2016). Promoting stress management and wellbeing in educators: Feasibility and efficacy of a school-based yoga and mindfulness intervention. Mindfulness, 7(1), 143-154. https://doi.org/10.1007/s12671-015$0451-2$.

Hue, M., \& Lau, N. (2015). Promoting well-being and preventing burnout in teacher education: A pilot study of a mindfulness-based programme for pre-service teachers in Hong Kong. Teacher Development, 19(3), 381-401. https://doi.org/10.1080/13664530.2015.1049748.

Hwang, Y.-S., Bartlett, B., Greben, M., \& Hand, K. (2017). A systematic review of mindfulness interventions for in-service teachers: A tool to enhance teacher wellbeing and performance. Teaching and Teacher Education, 64, 26-42. https://doi.org/10.1016/j.tate.2017.01.015.

Iani, L., Lauriola, M., Chiesa, A., \& Cafaro, V. (2019). Associations between mindfulness and emotion regulation: The key role of describing and nonreactivity. Mindfulness, 10(2), 366-375. https://doi.org/10.1007/s12671-018-0981-5.

Jennings, P. A. (2015a). Mindfulness for teachers: Simple skills for peace and productivity in the classroom (1st ed.). New York: W.W. Norton and Company.

Jennings, P. A. (2015b). Early childhood teachers' well-being, mindfulness and self-compassion in relation to classroom quality and attitudes towards challenging students. Mindfulness, 6(4), 732-743. https://doi.org/10.1007/s12671-014-0312-4.

Jennings, P. A., Brown, J. L., Frank, J. L., Doyle, S., Oh, Y., Davis, R., et al. (2017). Impacts of the CARE for Teachers program on teachers' social and emotional competence and classroom interactions. Journal of Educational Psychology, 109(7), 1010-1028. https://doi.org/10.1037/edu 0000187.

Jennings, P. A., \& DeMauro, A. A. (2017). Individual-level interventions: Mindfulness-based approaches to reducing stress and improving performance among teachers. In T. M. McIntyre, 
S. E. McIntyre, and D. J. Francis (Eds.), Educator stress (pp. 319-346). https://doi.org/10.1007/ 978-3-319-53053-6_14.

Jennings, P. A., Frank, J. L., Snowberg, K. E., Coccia, M. A., \& Greenberg, M. T. (2013). Improving classroom learning environments by Cultivating Awareness and Resilience in Education (CARE): Results of a randomized controlled trial. School Psychology Quarterly, 28(4), 374-390. https:// doi.org/10.1037/spq0000035.

Kabat-Zinn, J. (1994). Wherever you go, there you are: Mindfulness meditation in everyday life. New York: Hyperion.

Kerr, S. L., Lucas, L. J., DiDomenico, G. E., Mishra, V., Stanton, B. J., Shivde, G., Pero, A. N., Runyen, M. E., \& Terry, G. M. (2017). Is mindfulness training useful for pre-service teachers? An exploratory investigation. Teaching Education, 28(4), 349-359. https://doi.org/10.1080/104 76210.2017.1296831.

Lippelt, D. P., Hommel, B., \& Colzato, L. S. (2014). Focused attention, open monitoring and loving kindness meditation: Effects on attention, conflict monitoring, and creativity-A review. Frontiers in Psychology, 5. https://doi.org/10.3389/fpsyg.2014.01083.

Lomas, T., Medina, J. C., Ivtzan, I., Rupprecht, S., \& Eiroa-Orosa, F. J. (2017). The impact of mindfulness on the wellbeing and performance of educators: A systematic review of the empirical literature. Teaching and Teacher Education, 61, 132-141. https://doi.org/10.1016/j.tate.2016. 10.008.

Long, A. C. J., Renshaw, T. L., \& Camarota, D. (2018). Classroom management in an urban, alternative school: A comparison of Mindfulness and behavioral approaches. Contemporary School Psychology, 22(3), 233-248. https://doi.org/10.1007/s40688-018-0177-y.

Lutz, A., Slagter, H. A., Dunne, J. D., \& Davidson, R. J. (2008). Attention regulation and monitoring in meditation. Trends in Cognitive Sciences, 12(4), 163-169. https://doi.org/10.1016/j.tics.2008. 01.005.

Maynard, B. R., Solis, M. R., Miller, V. L., \& Brendel, K. E. (2017). Mindfulness-based interventions for improving cognition, academic achievement, behavior, and socioemotional functioning of primary and secondary school students. Campbell Systematic Reviews, 13(1), 1-144. https://doi. org/10.4073/CSR.2017.5.

McKeering, P., \& Hwang, Y.-S. (2019). A systematic review of mindfulness-Based school interventions with early adolescents. Mindfulness, 10(4), 593-610. https://doi.org/10.1007/s12671018-0998-9.

Mansfield, C. F., Beltman, S., Broadley, T., \& Weatherby-Fell, N. (2016). BRiTE: Building resilience in teacher education. Australia: Department of Education and Training.

Meiklejohn, J., Phillips, C., Freedman, M. L., Griffin, M. L., Biegel, G., Roach, A., et al. (2012). Integrating Mindfulness training into K-12 Education: Fostering the resilience of teachers and students. Mindfulness, 3(4), 291-307. https://doi.org/10.1007/s12671-012-0094-5.

Molloy Elreda, L., Jennings, P. A., DeMauro, A. A., Mischenko, P. P., \& Brown, J. L. (2019). Protective effects of interpersonal mindfulness for teachers' emotional supportiveness in the classroom. Mindfulness, 10(3), 537-546. https://doi.org/10.1007/s12671-018-0996-y.

Panksepp, J. (2005). Affective consciousness: Core emotional feelings in animals and humans. Consciousness and Cognition, 14(1), 30-80. https://doi.org/10.1016/j.concog.2004.10.004.

Prakash, R. S., Whitmoyer, P., Aldao, A., \& Schirda, B. (2017). Mindfulness and emotion regulation in older and young adults. Aging and Mental Health, 21(1), 77-87. https://doi.org/10.1080/136 07863.2015.1100158.

Roemer, L., Williston, S. K., \& Rollins, L. G. (2015). Mindfulness and emotion regulation. Current Opinion in Psychology, 3, 52-57. https://doi.org/10.1016/j.copsyc.2015.02.006.

Roeser, R. W., Schonert-Reichl, K. A., Jha, A., Cullen, M., Wallace, L., Wilensky, R., et al. (2013). Mindfulness training and reductions in teacher stress and burnout: Results from two randomized, waitlist-control field trials. Journal of Educational Psychology, 105(3), 787-804. https://doi.org/ 10.1037/a0032093.

Siegel, D. J., Siegel, M. W., \& Parker, S. C. (2016). Internal education and the roots of resilience: Relationships and reflection as the new R's of Education. In K. A. Schonert-Reichl \& R. W. 
Roeser (eds.), Handbook of Mindfulness in Education: Integrating Theory and Research into Practice (pp. 47-63). New York: Springer. https://doi.org/10.1007/978-1-4939-3506-2_4.

Semple, R. J., Droutman, V., \& Reid, B. A. (2017). Mindfulness goes to school: Things learned (so far) from research and real-world experiences. Psychology in the Schools, 54(1), 29-52. https:// doi.org/10.1002/pits.21981.

Shapiro, S. L. (2009). The integration of mindfulness and psychology. Journal of Clinical Psychology, 65(6), 555-560. https://doi.org/10.1002/jclp.20602.

Shapiro, S., Rechtschaffen, D., \& de Sousa, S. (2016). Mindfulness training for teachers. In K. Schonert-Reichl (Ed.), Handbook of mindfulness in education: Integrating theory and research into practice. New York: Springer.

Singh, N. N., Lancioni, G. E., Winton, A. S. W., Karazsia, B. T., \& Singh, J. (2013). Mindfulness training for teachers changes the behavior of their preschool students. Research in Human Development, 10(3), 211-233. https://doi.org/10.1080/15427609.2013.818484.

Skinner, E., \& Beers, J. (2016). Mindfulness and teachers' coping in the classroom: A developmental model of teacher stress, coping, and everyday resilience. In K. Schonert-Reichl \& R. Roeser (Eds.), Handbook of mindfulness in education. Springer, New York, NY: Mindfulness in Behavioral Health.

Šouláková, B., Kasal, A., Butzer, B., \& Winkler, P. (2019). Meta-Review on the effectiveness of classroom-based psychological interventions aimed at improving student mental health and wellbeing, and preventing mental illness. The Journal of Primary Prevention, 40(3), 255-278. https:// doi.org/10.1007/s10935-019-00552-5.

Todd, C., Cooksey, R., Davies, H., McRobbie, C., \& Brophy, S. (2019). Mixed-methods evaluation comparing the impact of two different mindfulness approaches on stress, anxiety and depression in school teachers. British Medical Journal Open, 9(7), e025686. https://doi.org/10.1136/bmj open-2018-025686.

Van Dam, N. T., van Vugt, M. K., Vago, D. R., Schmalzl, L., Saron, C. D., Olendzki, A., et al. (2018). Mind the hype: A critical evaluation and prescriptive agenda for research on mindfulness and meditation. Perspectives on Psychological Science, 13(1), 36-61. https://doi.org/10.1177/ 1745691617709589.

Walsh, Z. (2016). A meta-critique of mindfulness critiques: From McMindfulness to critical mindfulness. In R. E. Purser, D. Forbes, and A. Burke (Eds.), Handbook of mindfulness (pp. 153-166). https://doi.org/10.1007/978-3-319-44019-4_11.

Zenner, C., Herrnleben-Kurz, S., \& Walach, H. (2014). Mindfulness-based interventions in schools: A systematic review and meta-analysis. Frontiers in Psychology, 5. https://doi.org/10.3389/fpsyg. 2014.00603.

Zimmerman, A. (2018). Considerating the prospect of cultivating mindfulness in teacher education. Issues in Teacher Education, 27(1), 57-72.

Open Access This chapter is licensed under the terms of the Creative Commons Attribution 4.0 International License (http://creativecommons.org/licenses/by/4.0/), which permits use, sharing, adaptation, distribution and reproduction in any medium or format, as long as you give appropriate credit to the original author(s) and the source, provide a link to the Creative Commons license and indicate if changes were made.

The images or other third party material in this chapter are included in the chapter's Creative Commons license, unless indicated otherwise in a credit line to the material. If material is not included in the chapter's Creative Commons license and your intended use is not permitted by statutory regulation or exceeds the permitted use, you will need to obtain permission directly from the copyright holder. 